\title{
Disentangling the Frequency and Severity of Bullying and Victimization in the Association with Empathy
}

Tirza H. J. van Noorden ${ }^{1}$, William M. Bukowski ${ }^{2}$, Gerbert J. T. Haselager ${ }^{1}$, Tessa A. M. Lansu ${ }^{1}$ and Antonius H. N. Cillessen ${ }^{1}$

${ }^{1}$ Radboud University Nijmegen

${ }^{2}$ Concordia University

\begin{abstract}
This study disentangled the frequency and perceived severity of experienced bullying and victimization by investigating their associations with cognitive and affective empathy. Participants were 800 children (7-12 years old) from third-to fifth-grade classrooms who completed self-report measures of the frequency and perceived severity of their bullying and victimization and of cognitive and affective empathy. Results showed that the frequency and perceived severity of bullying were moderately correlated in the entire sample but unrelated within the subsample of bullies. Frequency and perceived severity of victimization were significantly and positively correlated in the entire sample (moderate effect) and the subsample of victims (small effect). Frequent, but not severe, bullies reported less cognitive empathy than non-bullies whereas both frequent and severe victims reported more affective empathy than non-victims. Within subsamples of bullies and victims, frequency of bullying was negatively associated with cognitive and affective empathy, and perceived severity of bullying was positively associated with affective empathy. Frequency of victimization was not associated with cognitive and affective empathy, but perceived severity of victimization was positively associated with both forms of empathy.
\end{abstract}

Keywords: bullying; victimization; frequency; severity; empathy

This work is part of the project 'Empathy \& Bullying in Childhood' (file number: 431-09-029) funded by the National Initiative Brain and Cognition (NIBC) of The Netherlands Organization for Scientific Research (NWO). The authors are grateful to the children, parents, and school administrators who made this research possible. In addition, the authors would like to thank Giovanni D. M. ten Brink for his help with the measures.

Correspondence should be addressed to Tirza H. J. van Noorden, Behavioural Science Institute, Radboud University Nijmegen, P.O. Box 9104, 6500 HE Nijmegen, The Netherlands. Email: t.vannoorden@psych.ru.nl 


\section{Introduction}

Bullying prevention and intervention programs have often incorporated empathy training as an essential element (for an overview, see Farrington \& Ttofi, 2009). The underlying assumption of such programs seems to be that bullies are deficient in empathy or even lack it completely. However, research on the association of bullying and victimization with empathy shows inconsistent findings (for a review, see van Noorden, Haselager, Cillessen, \& Bukowski, 2015). This inconsistency may be partly due to the various ways in which bullying is measured. Bullying is typically defined as a subtype of aggressive behavior in which an individual or group intentionally causes harm to a relatively powerless person repeatedly and over time (Olweus, 2010; Salmivalli, 2010; Salmivalli \& Peets, 2009); victimization can be defined as the experience of being the target of bullying. The 'repeatedly and over time' element of this definition has resulted in the use of frequency as a key feature of many measures of bullying. By relying on the measures that invoke the element of frequency to identify bullying and victimization one implicitly assumes that frequency is an indication of perceived severity. Recent research, however, shows that more frequent victimization is not necessarily perceived as more severe (Chen, Cheng, Wang, \& Hsueh, 2013). In this study, the effects of frequency and perceived severity are contrasted with regards to cognitive and affective empathy to assess their relative importance.

\section{Antisocial Behavior and Empathy}

Empathy can be defined as a cognitive trait referring to a person's ability to understand another person's emotions (e.g., Hogan, 1969) or as an affective trait referring to a person's capacity to experience another person's emotions (e.g., Mehrabian \& Epstein, 1972). Today, empathy is typically conceptualized as a multidimensional construct with the cognitive and affective components combined (Cohen \& Strayer, 1996; Davis, 1983). It has been well established that elevated levels of empathy are associated with prosocial behavior (e.g., Eisenberg \& Miller, 1987). Findings on the association between empathy and antisocial behavior have been less conclusive. Miller and Eisenberg (1988) found in their review that affective empathy was negatively associated with antisocial behavior, but only when empathy was measured with questionnaires. In another review, which focused specifically on studies that used questionnaires, Jolliffe and Farrington (2004) found a stronger negative association of offending with cognitive than with affective empathy. In a review on the association between aggressive or delinquent behavior and affective empathy in children and adolescents, Lovett and Sheffield (2007) found a negative association between affective empathy and aggression, especially when measured with questionnaires, but only in older children and adolescents and not in younger children.

Bullying is a specific form of childhood antisocial behavior that has received increased attention due to its high prevalence (e.g., Stassen Berger, 2007) and its detrimental effects on physical and mental health (e.g., Rigby, 2000; Ttofi \& Farrington, 2008). Van Noorden et al. (2015) systematically reviewed the association between bullying involvement and empathy based on the findings of 40 studies using questionnaires. This review revealed mixed results regarding the association between bullying and cognitive empathy. Some studies reported a negative association (e.g., Belacchi \& Farina, 2012; Poteat \& Espelage, 2005) whereas others found 
no association (e.g., Caravita, Di Blasio, \& Salmivalli, 2009; Stavrinides, Georgiou, $\&$ Theofanous, 2010). In contrast, there was high consensus among studies on a negative association between bullying and affective empathy (e.g., Belacchi \& Farina, 2012; Stavrinides et al., 2010). Together these findings suggest that children involved in bullying are not necessarily incapable of understanding others' feelings, but do appear to experience others' feelings to a smaller extent.

Van Noorden et al. (2015) also reviewed the association of empathy with being the target, rather than the perpetrator, of bullying. Similar to bullying, mixed results were found for the association of victimization with cognitive empathy, with studies reporting a negative association (e.g., Kokkinos \& Kipritsi, 2012; Poteat \& Espelage, 2005) or no association (e.g., Belacchi \& Farina, 2012; Ciucci \& Baroncelli, 2014). Regarding the association of victimization with affective empathy, the majority of studies indicated no association (e.g., Belacchi \& Farina, 2012; Poteat \& Espelage, 2005). These findings suggest that victimized children are just as capable as non-victimized children to experience what others feel, but have more difficulty with understanding others' feelings.

\section{Frequency and Perceived Severity}

The inconsistent findings on the associations of bullying and victimization with empathy partly may have been caused by the way bullying involvement has been operationalized. Although the conceptual definition of bullying is solid, operational definitions are heterogeneous. This discrepancy between conceptual and operational definitions is especially true for the 'repeatedly and over time' element. In most studies, the frequency of incidents determines whether an aggressive situation is classified as bullying or victimization. To illustrate, some of the most common bullying and victimization questionnaires use temporal categories as response options. For example, the revised Olweus Bully/Victim Questionnaire (Olweus, 1996) has the response options: 'never', 'only once or twice', '2-3 times a month' (replacing the 'sometimes' category used in earlier versions of the scale), 'once per week', and 'several times per week'. In some studies, bullying or victimization has been identified when incidents occurred at least 2-3 times a month (e.g., Park, 2013; Williford, Boulton, \& Jenson, 2014) whereas in other studies a threshold of incidents having occurred only once or twice has been used (e.g., Jolliffe \& Farrington, 2006b, 2011; Sticca, Ruggieri, Alsaker, \& Perren, 2013).

Research by Jolliffe and Farrington (2006b, 2011) shows that the frequency threshold that is used affects the association between bullying involvement and empathy. They compared non-bullies, occasional bullies ('once or twice'), and frequent bullies ('sometimes' or more often) on cognitive and affective empathy. Overall, the results revealed that bullies in general (i.e., occasional and frequent bullies combined) did not differ from non-bullies on cognitive and affective empathy. However, frequent bullies reported less cognitive empathy (males only) as well as less affective empathy (males and females) than non-bullies. Furthermore, frequent bullies reported less affective, but not cognitive, empathy than occasional bullies. Combining these results, one could conclude that children who are involved in bullying have less empathy than children who are not involved in bullying, but only when they bully frequently.

The frequency of bullying and victimization is typically confused with its perceived severity. Perceived severity is likely a powerful index of the seriousness of 
bullying and victimization incidents. It can be defined as an individual's implicit perception of the impact or effect of an incident or series of incidents with respect to the degree of harm caused to oneself and others. Perceived severity is sensitive to interpretations and situational factors, such as the publicity and anonymity of the incidents (Sticca \& Perren, 2013). Despite the distinct conceptualization of frequency from perceived severity, many studies have assumed the attributes to be interchangeable. There are studies in which bullying or victimization incidents that occur at least once a week have been explicitly referred to as more serious or severe than those that happen less often (e.g., Borg, 1999; Boulton \& Underwood, 1992; Slee, 1994). Another study explicitly conflated frequency and perceived severity by defining bullying as 'mildly severe' when incidents only occurred once, 'moderately severe' when incidents occurred over time and resulted in reciprocated aggression, and 'very severe' when incidents occurred over time and involved multiple bullies who were bigger or older and resulted in obvious distress (Raskauskas, 2005).

Although frequency may be an indicator of perceived severity in some circumstances, it is debatable whether being called a disrespectful name twice a week is experienced as twice as severe as being called a disrespectful name once a week. This claim that the frequency of bullying and victimization does not necessarily determine the perceived severity finds support in the literature that shows that the most frequent forms of bullying are not considered to be the most severe ones. Verbal bullying occurs more frequently than physical bullying (e.g., Scheithauer, Hayer, Petermann, \& Jugert, 2006; Whitney \& Smith, 1993), but is considered less severe by students (measured with hypothetical scenarios; Maunder, Harrop, \& Tattersall, 2010).

Recently, Chen et al. (2013) investigated the correspondence between frequency and perceived severity of victimization directly. Instead of using hypothetical scenarios, they focused on participants' own actual victimization experiences. Overall, boys reported their victimization as more frequent whereas girls reported their victimization as more severe. More importantly, a non-significant association was found between frequency and perceived severity of victimization $(r=-.11)$, supporting that they cannot be equated and should be investigated separately.

\section{Present Study}

This study aimed to disentangle frequency and perceived severity of bullying and victimization by examining their associations with cognitive and affective empathy. The first research question that was addressed is whether children who are occasionally or frequently involved in bullying and victimization as well as children who are mildly or severely involved differ in cognitive and affective empathy from children who are not involved? We expected children who were frequently involved in bullying to report less cognitive and affective empathy than children who were not involved in bullying (based on Jolliffe \& Farrington, 2011) and investigated whether the same was true for involvement in victimization (based on Ciucci \& Baroncelli, 2014; Poteat \& Espelage, 2005). Because this study was the first to investigate cognitive and affective empathy among non-involved children, mildly involved children, and severely involved children, we explored whether these groups differed from each other on bullying and victimization separately.

The second research question denoted whether frequency and perceived severity have unique associations with cognitive and affective empathy for children who are 
involved in bullying and victimization. To test these associations as well as the additive effect of perceived severity beyond the effect of the commonly used frequency, hierarchical regression analyses were conducted separately for bullying and victimization. Children who were not involved in bullying or victimization were not included in the analyses as they do not have scores on the frequency and severity of bullying or victimization, leaving us to focus solely on children who were involved in varying degrees of frequency and perceived severity. We expected a negative association of the frequency of bullying with affective, but not cognitive, empathy (based on Jolliffe \& Farrington, 2006b). We explored the associations of victimization with cognitive and affective empathy (based on, e.g., Ciucci \& Baroncelli, 2014; Poteat \& Espelage, 2005). Furthermore, we explored whether and how the perceived severity is associated with cognitive empathy and affective empathy beyond the association of the frequency with cognitive and affective empathy, separately for bullying and victimization.

In all analyses, gender was taken into account because of the different associations between the frequency of bullying and empathy found for boys and girls (Jolliffe \& Farrington, 2006b, 2011) as well as the differences between boys and girls in the frequency and perceived severity of victimization (Chen et al., 2013).

\section{Method}

\section{Participants}

This study is part of a larger project (see also van Noorden, Haselager, Cillessen, \& Bukowski, 2014), in which the potential sample consisted of a pool of 838 children recruited from 34 third- to fifth-grade classrooms of 11 elementary schools. The schools were located in villages and cities in the Eastern part of The Netherlands with average socioeconomic status. School principals and teachers agreed to participate in the study. As approved by the ethical review committee of the first author's home institution, parents and children were informed about the nature and procedure of the study with a letter and could indicate if they did not want their child to participate. Nine children were not allowed to participate by their parents; no children objected to participation themselves or stopped during the study. Twenty-nine children were absent during data collection, resulting in a final sample of 800 children (50.5\% boys) between 7 and 12 years $(M=10.01, S D=1.01)$, with 776 children $(97.0 \%)$ born in The Netherlands. All children received a small gift and teachers received a $€ 10$ voucher as a token of appreciation.

\section{Procedure}

During the second half of the school year, all children in each classroom completed the questionnaires simultaneously on individual 10 inch netbook computers (see van den Berg \& Cillessen, 2013). They sat at separate desks with partitioning screens on both sides to prevent them from seeing each other's screens. To further enhance privacy, we emphasized verbally that the partitioning screens marked children's own personal space and that the data would be processed anonymously and handled confidentially. The nature of the study was explained and it was indicated that we were interested in children's opinions and that there were no right or wrong answers. Children were not allowed to talk to each other during the data collection but they could ask the researchers questions or stop their participation at any time. 


\section{Measures}

Frequency and Perceived Severity of Bullying and Victimization. The bullying definition was provided to the children (cf., Olweus, 1996) and was discussed interactively by asking the children to give examples of different forms (e.g., verbal, physical, relational, and cyber). Measurement of frequency and perceived severity of bullying and victimization took place in three steps. First, two self-report questions were asked: 'Who in your classroom have you bullied?' and 'Who in your classroom has bullied you?'. Children were asked to answer the question with regard to the current school year. Children could nominate none up to all of their classmates. The names of the classmates, excluding their own name, were presented on the computer screen in randomized order between participants, but in a fixed order within participants.

Second, based on the measurement approach of the Revised Olweus Bully/Victim Questionnaire (Olweus, 1996) we made a further distinction between different forms of bullying/victimization. Children were asked, separately for each nominated classmate, to identify the form in which the children had bullied that classmate (bullying) or had been bullied by that classmate (victimization). Five options were given: (a) pushed, kicked, or hit (physical), (b) called names (verbal), (c) gossiped (relational), (d) excluded or ignored (relational), (e) via the Internet or phone (cyber). Children could select one up to all five forms.

Third, children were asked, separately for each nominated classmate and form of bullying or victimization, to indicate frequency and perceived severity. Frequency was measured by asking how often each bullying or victimization had occurred ('How many times have you bullied [nominated classmate] by [identified form]?' 'How many times has [nominated classmate] bullied you by [identified form]?', respectively). Children could answer by filling in the number and choosing the corresponding period (day, week, month, year; presented in a dropdown menu). Perceived severity was measured by asking how severe they thought each indicated form of bullying or victimization was. Children could answer this question by clicking on a visual analogue scale, coded as a 100-point scale, with anchors 'not severe' [1] and 'very severe' [100].

Afterwards, to make the answers comparable, all frequency scores were converted to weeks (e.g., once a week became a score of 1; three times per month became 0.69). For each child a mean frequency score was calculated by dividing the sum of frequencies by the number of nominated classmates for the frequency question. A mean score of perceived severity was calculated by dividing the total sum by the number of nominated classmates for the perceived severity question.

The frequency and perceived severity scores were screened for outliers, defined as values greater than $3 S D$ above or below the mean. Outlier values $(n=7)$ were winsorized at $3 S D$ below or above the mean (see Tukey, 1977). Based on their frequency and perceived severity scores, children were also assigned to a noninvolved, occasional, or frequent group as well as a non-involved, mild, or severe group. Children with frequency and perceived severity scores of 0 were assigned to the non-involved group (a score of 0 on one of the variables automatically implied a score of 0 on the other variable). Children with frequency scores of more than 0 and less than 1 (indicating less than once a week) were considered the occasional group. Children with frequency scores of 1 or more (indicating once a week or more) were considered the frequent group. Children with perceived severity scores 
182 Tirza H. J. van Noorden, William M. Bukowski, Gerbert J. T. Haselager et al.

Table 1. Correlations Among Study Variables in the Full Sample

\begin{tabular}{lcccccc}
\hline & $M(S D)$ & 1. & 2. & 3. & 4. & 5. \\
\hline $\begin{array}{l}\text { 1. Bullying } \\
\text { Frequency }\end{array}$ & $1.39(7.33)$ & - & & & \\
$\begin{array}{l}\text { 2. Bullying } \\
\text { Severity }\end{array}$ & $9.06(20.02)$ & $.32 * * *$ & - & & \\
$\begin{array}{l}\text { 3. Victimization } \\
\text { Frequency }\end{array}$ & $4.98(12.33)$ & .06 & $.09 * *$ & - & & \\
$\begin{array}{l}\text { 4. Victimization } \\
\text { Severity }\end{array}$ & $31.12(33.52)$ & -.01 & $.21 * * *$ & $.39 * * *$ & - & \\
$\begin{array}{l}\text { 5. Cognitive } \\
\text { Empathy }\end{array}$ & $3.77(0.64)$ & $-.17 * * *$ & $-.09^{*}$ & .03 & .05 & - \\
$\begin{array}{l}\text { 6. Affective } \\
\text { Empathy }\end{array}$ & $2.83(0.72)$ & $-.11^{* *}$ & -.03 & $.11^{* *}$ & $.16^{* * *}$ & $.43^{* * *}$ \\
\hline
\end{tabular}

Note. Frequency means represent the number of bullying/victimization incidents per week; Severity means represent the score on 100-point scale; Empathy means represent the score on five-point scale. ${ }^{*} p<.05 .{ }^{* *} p<.01 .{ }^{* * *} p<.001$.

between 1 and 50 (lower half of the scale) formed the mild group and children with perceived severity scores between 51 and 100 (upper half of the scale) formed the severe group. This procedure was conducted separately for bullying and victimization.

Empathy. Empathy was measured with an adapted version of the Basic Empathy Scale (BES; Jolliffe \& Farrington, 2006a). Like the original BES, the adapted scale consists of 20 items, measuring cognitive empathy (9 items) and affective empathy (11 items). An example cognitive item is 'I can understand my friend's happiness when she/he does well at something'; an example affective item is 'After being with a friend who is sad about something, I usually feel sad'. Originally negatively formulated questions were reformulated into positive formulations. Participants indicated to what extent they agreed with each statement on a five-point Likert scale $(1=$ strongly disagree; 5 = strongly agree $)$. The reliability of both scales was high (both $\alpha \mathrm{s}=.83$ ).

\section{Results}

\section{Descriptives}

The first research question focuses on the associations of frequency and perceived severity of bullying and victimization with cognitive and affective empathy in the full sample. The correlations among all study variables in the full sample are shown in Table 1. It is noteworthy that frequency and perceived severity of both bullying and victimization were moderately correlated $(r=.32, p<.001$, and $r=.39, p<$ .001 , respectively). None of the correlations differed between boys and girls when tested with Fisher's $r$-to- $Z$ transformations. 
Table 2. N, Mean, and Standard Deviation of Cognitive and Affective Empathy for Frequency and Severity Groups of Bullying and Victimization

\begin{tabular}{lcccccc}
\hline & & \multicolumn{2}{c}{ Frequency } & & \multicolumn{2}{c}{ Severity } \\
\cline { 3 - 4 } & \multirow{2}{nnnnnn}{$\begin{array}{c}\text { Not } \\
\text { Involved }\end{array}$} & $\begin{array}{c}\text { Occasionally } \\
\text { Involved }\end{array}$ & $\begin{array}{c}\text { Frequently } \\
\text { Involved }\end{array}$ & & $\begin{array}{c}\text { Mildly } \\
\text { Involved }\end{array}$ & $\begin{array}{c}\text { Severely } \\
\text { Involved }\end{array}$ \\
\hline Bullying & $N=597$ & $N=102$ & $N=101$ & $N=130$ & $N=73$ \\
Cognitive & $3.80^{\mathrm{a}}(0.64)$ & $3.75(0.56)$ & $3.60^{\mathrm{a}}(0.73)$ & $3.68(0.57)$ & $3.66(0.78)$ \\
Affective & $2.86(0.71)$ & $2.80(0.75)$ & $2.68(0.73)$ & $2.69(0.68)$ & $2.82(0.84)$ \\
Victimization & $N=338$ & $N=155$ & $N=307$ & $N=183$ & $N=279$ \\
Cognitive & $3.77(0.66)$ & $3.72(0.56)$ & $3.79(0.67)$ & $3.73(0.57)$ & $3.79(0.67)$ \\
Affective & $2.73^{\mathrm{bc}}(0.70)$ & $2.84(0.67)$ & $2.92^{\mathrm{b}}(0.74)$ & $2.79^{\mathrm{d}}(0.70)$ & $2.96^{\mathrm{cd}}(0.72)$ \\
\hline
\end{tabular}

Note. Means with identical letters were significantly different from each other; standard deviations are indicated in parentheses.

The second research question deals with the unique associations of frequency and perceived severity with cognitive and affective empathy in the subsample of children involved in bullying and/or victimization. Within this subsample of children involved in bullying $(n=203 ; 39.4 \%$ girls $)$ and victimization $(n=462$; $51.5 \%$ girls), the correlation between continuous frequency and continuous perceived severity was non-significant for bullies, $r=.11, p>.05$. For victims, a weak positive correlation was found, $r=.20, p<.001$. Again, no differences between boys and girls were found regarding these associations, when tested with Fisher's $r$-to- $Z$ transformations.

\section{Comparisons of Non-involved with Frequency and Perceived Severity Groups on Empathy}

To answer the first research question, the cognitive and affective empathy scores of children who were not involved in bullying were compared to children who were occasionally and frequently involved, as well as with children who were mildly and severely involved. The group means are presented in Table 2. Separate Analysis of Variances were conducted for both bullying and victimization. To account for possible differences between boys and girls, gender was included as an independent variable and moderator. Significant effects of frequency and perceived severity were followed by post hoc tests in the form of multiple comparisons with Bonferroni correction.

Bullying. For cognitive empathy, a main effect of frequency was found, $F(2,794)$ $=3.50, p=.031, \eta_{\text {partial }}^{2}=.009$. The post hoc test showed that frequent bullies reported significantly less cognitive empathy than non-bullies $(p=.014)$. The results did not reveal a main effect of perceived severity on cognitive empathy. In addition, gender did not have a main effect and did not interact with frequency or perceived severity.

For affective empathy, there were no main effects of frequency or perceived severity or interactions of frequency and perceived severity with gender. However, 
there was a main effect of gender when controlling for frequency, $F(1,794)=$ $73.69, p<.001, \eta_{\text {partial }}^{2}=.085$, as well as when controlling for perceived severity, $F(1,794)=75.32, p<.001, \eta^{2}$ partial $=.087$. Inspection of the means indicated that girls $(M=3.09)$ reported more affective empathy than boys $(M=$ 2.57).

Victimization. For cognitive empathy, there were no main effects of frequency or perceived severity or interactions of frequency and perceived severity with gender. There was a main effect of gender when controlling for frequency, $F(1,794)=$ 4.79, $p=.029, \eta^{2}$ partial $=.006$, and when controlling for perceived severity, $F(1$, $794)=5.73, p=.017, \eta_{\text {partial }}^{2}=.007$. Inspection of the means indicated that girls $(M=3.82)$ reported more cognitive empathy than boys $(M=3.71)$.

A significant effect of frequency was found for affective empathy, $F(1,794)=$ 4.71, $p=.009, \eta_{\text {partial }}^{2}=.012$. Multiple comparisons indicated that frequent victims, but not occasional victims, showed significantly more affective empathy than non-victims when controlling for gender $(p=.001)$. There was also a main effect of perceived severity, $F(1,794)=9.57, p<.001, \eta_{\text {partial }}^{2}=.024$. Post hoc comparisons indicated that severe victims showed more affective empathy than nonvictims $(p<.001)$ as well as mild victims $(p=.015)$. In addition, the main effect of gender was significant when controlling for frequency, $F(1,794)=98.55, p<$ $.001, \eta_{\text {partial }}^{2}=.110$, and when controlling for perceived severity, $F(1,794)=$ $116.65, p<.001, \eta_{\text {partial }}^{2}=.128$. Inspection of the means indicated that girls $(M=$ $3.09)$ reported more affective empathy than boys $(M=2.57)$.

\section{Unique Associations of Frequency and Perceived Severity and Interaction with Empathy}

In order to test the unique effects of frequency and perceived severity when controlling for gender, four separate hierarchical regression analyses were conducted with the continuous frequency and perceived severity scores of involved children as predictor variables and cognitive or affective empathy as the outcome variable. That is, the analyses were performed separately for cognitive empathy and affective empathy and separately for bullying and victimization. To test the effect of severity beyond the effect of the commonly used frequency we entered them in separate steps. In Step 1 of each analysis, gender was entered (dummy coded; $0=$ boys, $1=$ girls). The more commonly used frequency indicator was entered in Step 2. Perceived severity was entered in Step 3. Step 4 contained all two-way interactions between frequency, perceived severity, and gender. Step 5 contained the three-way interaction. Because Steps 4 and 5 did not reveal significant results in any of the analyses, they were not further considered. The results of Steps 1-3 of the four hierarchical regression analyses are presented in Table 3.

Bullying. In the analysis of cognitive empathy, Step 1 showed no effect of gender, indicating that boys and girls who bully did not differ in their levels of cognitive empathy. Step 2 revealed a significant negative association of frequency, meaning that more frequent bullying was associated with lower levels of cognitive empathy. Step 3 showed no significant effect of perceived severity, indicating that the perceived severity of bullying was not associated with cognitive empathy beyond the effect of the frequency of bullying. 
Table 3. Results for the Regression of Cognitive and Affective Empathy on Gender and the Frequency and Severity of Bullying and Victimization

\begin{tabular}{|c|c|c|c|c|c|c|c|c|}
\hline & \multicolumn{4}{|c|}{ Bullying } & \multicolumn{4}{|c|}{ Victimization } \\
\hline & \multicolumn{2}{|c|}{$\begin{array}{l}\text { Cognitive } \\
\text { Empathy }\end{array}$} & \multicolumn{2}{|c|}{$\begin{array}{l}\text { Affective } \\
\text { Empathy }\end{array}$} & \multicolumn{2}{|c|}{$\begin{array}{l}\text { Cognitive } \\
\text { Empathy }\end{array}$} & \multicolumn{2}{|c|}{$\begin{array}{l}\text { Affective } \\
\text { Empathy }\end{array}$} \\
\hline & $\Delta R^{2}$ & $\beta$ & $\Delta R^{2}$ & $\beta$ & $\Delta R^{2}$ & $\beta$ & $\Delta R^{2}$ & $\beta$ \\
\hline Step 1 & $<.01$ & & $.17 * * *$ & & $<.01$ & & $.11 * * *$ & \\
\hline Gender & & .03 & & $.41 * * *$ & & .06 & & $.33 * * *$ \\
\hline Step 2 & $.09 * * *$ & & $.02 *$ & & $<.01$ & & $<.01$ & \\
\hline Frequency & & $-.29 * * *$ & & $-.15^{*}$ & & .04 & & .08 \\
\hline Step 3 & $<.01$ & & $.02 *$ & & $.01 *$ & & $.03 * * *$ & \\
\hline Severity & & $<.01$ & & $.15^{*}$ & & $.12 *$ & & $.08 * * *$ \\
\hline Total $R^{2}$ & $.09 * *$ & & $.21 * * *$ & & $.02 *$ & & $.15 * * *$ & \\
\hline
\end{tabular}

$* p<.05 . * * p<.01 .{ }^{* * *} p<.001$.

In the analysis of affective empathy, Step 1 showed a significant effect of gender; girls who bully reported more affective empathy than boys who bully. Step 2 showed a significant negative association of frequency, indicating that more frequent bullying was associated with lower levels of affective empathy. Step 3 showed a significant positive association of perceived severity, meaning that more severe bullying was associated with higher levels of affective empathy beyond the effect of the frequency of bullying.

Victimization. The analysis of cognitive empathy showed that in Step 1 gender was not significantly associated with cognitive empathy; victimized boys and girls did not differ in their levels of cognitive empathy. Step 2 showed no significant effect of frequency, indicating that the frequency of victimization incidents was not associated with cognitive empathy. Step 3 showed a significant positive effect of perceived severity, indicating that more severe victimization was associated with higher levels of cognitive empathy beyond the effect of the frequency of victimization.

For affective empathy, Step 1 revealed a significant effect of gender, with victimized girls reporting more affective empathy than victimized boys. Step 2 showed no significant effect of frequency, indicating that the reported frequency of victimization incidents was not associated with affective empathy. Step 3 revealed a significant positive association of perceived severity, meaning that more severe victimization was associated with higher levels of affective empathy beyond the effect of the frequency of victimization.

\section{Discussion}

This study examined the associations of frequency and perceived severity of bullying and victimization with empathy. Two research questions were addressed. The first focused on a comparison of the empathy levels of non-involved children to 
those of occasionally and frequently involved children and to those of mildly and severely involved children. The second research question addressed the unique associations of frequency and perceived severity with empathy and the additive value of perceived severity beyond frequency among involved children. Both research questions were investigated separately for bullying and victimization and will be discussed accordingly.

\section{Disentangling Frequency and Perceived Severity of Bullying}

When focusing on the entire sample of children, including those who were not involved in bullying, frequency and perceived severity of bullying were moderately associated. However, among children who were actually involved in bullying, frequency of bullying was not associated with perceived severity. This indicates that bullies do not regard their more frequent bullying incidents to be more severe than their less frequent bullying incidents.

The distinction between the frequency and perceived severity of bullying is also reflected in the finding that frequent bullies differ from non-bullies in cognitive empathy whereas severe bullies did not differ from non-bullies in cognitive empathy. Neither frequent nor severe bullies differed from non-bullies in affective empathy. These findings demonstrate that children who bully frequently and severely are just as able to experience others' emotions as children who do not bully whereas children who bully frequently, but not severely, are less able to understand others' emotions than are children who are not involved in bullying. An interpretation of these findings is that children who have difficulty with understanding how others feel bully more because they are unaware of how their actions impact their victims.

Among children involved in bullying, frequency of bullying was negatively associated with both cognitive and affective empathy (partially in line with Jolliffe \& Farrington, 2006b). In this study, perceived severity of bullying was positively associated with affective empathy but not with cognitive empathy. The finding that the associations of frequency and perceived severity of victimization with affective empathy are in opposite directions, emphasizes that frequency and perceived severity of bullying are different constructs. Regarding the negative association between frequency of bullying and empathy, it seems plausible that having lower levels of cognitive and affective empathy leads children to bully others more frequently as they are not likely to foresee the negative consequences of their actions for others. However, as this study was correlational, it is also possible that bullying others more frequently leads to less cognitive and affective empathy. In this case lowered empathy could serve as a way to cope with the negative cognitions and feelings the bully must experience.

The positive association between bullying perceived severity and affective empathy suggests that when children who are able to experience others' emotions bully, regardless of how frequently, they perceive their behavior as more severe. Based on the positive association between affective empathy and shame (Leith \& Baumeister, 1998), it is possible that children with higher levels of affective empathy feel more ashamed of their bullying behavior and, therefore, perceive it as more severe. An alternative explanation is that bullies who are able to feel what their victims feel are better able to harass others in quality, rather than quantity, by targeting their victims' vulnerabilities. 


\section{Disentangling Frequency and Perceived Severity of Victimization}

The frequency and perceived severity of victimization were moderately positively associated in the entire sample, but weakly associated in the subsample involved in victimization. This indicates that the frequency and perceived severity of victimization are related, but cannot be equated to each other.

Regarding the first research question, consistent with Poteat and Espelage (2005), we found that occasional and frequent victims as well as mild and severe victims did not differ in cognitive empathy from children who were not victimized. In addition, in line with Caravita, Di Blasio, and Salmivalli (2010), frequent victims but also severe victims reported more affective empathy than non-victims. Together, these findings indicate that we have no reason to believe that victims differ from children who are not victimized in their ability to understand others' emotions whereas they do appear to experience others' emotions to a larger extent than children who are not victimized. It is possible that children who are more able to experience others' emotions are more sensitive to emotions in general. If these children also display their emotions to a larger extend, this may make them more appealing to bullies who proactively want to hurt them and see the result of their bullying, in turn resulting in more frequent and severe victimization. This potential general sensitivity to emotions could also lead them to perceive their victimization as more frequent and severe because they experience their emotions more intensely. It is also possible that these empathic children perceive their victimization as more frequent and severe than less empathic children because they have more experience with sensing how other victims feel after being bullied, making these feelings more salient or accessible to them.

Among self-reported victims, frequency of victimization was not associated with cognitive or affective empathy (in line with Belacchi \& Farina, 2012; Poteat \& Espelage, 2005). That is, although frequent victims reported higher levels of affective empathy than non-victimized children, children who are victimized more frequently do not differ in cognitive or affective empathy from children who are victimized less frequently. In contrast, we found positive associations of perceived severity of victimization with cognitive and affective empathy. This indicates that, in addition to severe victims reporting higher levels of affective empathy than nonvictims, children who perceive their victimization as more severe reported higher levels of understanding and experiencing others' emotions than children who perceive their victimization as less severe. It is possible that being victimized and the emotions that follow from it cause children to be better able to understand and experience how others feel as well. At the same time, it is also likely that very empathic children experience being bullied as more severe, because they are more in contact with emotions in general, including their own.

\section{Disentangling Frequency and Perceived Severity in Bullying vs. Victimization}

This study demonstrated that the frequency and perceived severity of bullying and victimization are quantitatively different and have unique associations with cognitive and affective empathy. Throughout the study, it appears that in the association between bullying and empathy it is the frequency that plays a main role whereas in the association between victimization and empathy it is the perceived severity that plays the largest role. For example, frequency of bullying is associated with 
cognitive and affective empathy whereas frequency of victimization is not. For the subsample of victims, the severity of their victimization is associated with cognitive and affective empathy whereas for the subsample of bullies, the severity of their bullying is only associated with one of the two empathy forms (i.e., affective). The finding that frequency plays a larger role in bullying than in victimization is in line with the review by van Noorden et al. (2015). They concluded, based on studies that often relied on frequency-based measures, that bullying is generally negatively associated with empathy whereas there was less evidence for an association of victimization with empathy. Furthermore, by using self-report measures, bullies reported on behavior that they caused whereas victims reported on behavior that happened to them. This focus on experiences emphasizes the more external nature of bullying and the more internal nature of victimization, which corresponds with the more observable nature of frequency and the more personal and implicit nature of perceived severity.

\section{Gender Differences}

Throughout the study, gender differences in empathy were found. In general, girls reported more cognitive and affective empathy than boys, in line with previous literature using self-reports (for a review, see Rose \& Rudolph, 2006). When specifically looking at children involved in bullying or victimization, girls reported more affective empathy than boys, but did not differ from boys in cognitive empathy. Despite these main effects of gender on empathy, no interactions with frequency or perceived severity were found. This indicates that the associations of frequency and perceived severity of bullying involvement with empathy are similar for boys and girls.

\section{Limitations and Future Directions}

Due to the correlational nature of the study we cannot draw conclusions on the directionality of the found associations. Adopting experimental designs in future research on bullying and victimization is highly unlikely as this raises serious ethical concerns. However, longitudinal studies may shed more light on the development of the associations of the frequency and perceived severity of bullying and victimization with cognitive and affective empathy.

The sole reliance on self-reports may be considered a limitation as some of these victims may not have been identified as victims by their peers. However, this is not necessarily problematic for the current study as we were specifically interested in the frequency and severity of bullying and victimization as perceived by children themselves, regardless of whether this is in accordance with what the peer group thinks. Overall, self-reports and peer-reports tend to be moderately correlated (e.g., Bouman et al., 2012; Branson \& Cornell, 2009). In future research, both methods could be included to investigate differences in perspectives on frequency and severity of bullying and victimization. The view of the peer group in the frequency and perceived severity of bullying and victimization, apart from outsiders' own experiences, may also be extremely valuable to consider in future research. That is, the peer group may perceive things differently, and aggressive children may underestimate, or underreport, their own bullying behaviors.

Moreover, it is possible that we have been too conservative in our frequency measure by taking mean scores rather than sum scores, resulting in a potential 
underestimation of the frequency of bullying and victimization. However, we needed to take into account that multiple forms of bullying may co-occur during a single session. Using sum scores would disregard this possibility. In addition, mean scores, unlike sum scores, are not dependent on the number of given nominations. In this way, the severity score is unrelated to the classroom size, and the number of bullies nominated.

The explained variance by frequency and severity of bullying and victimization is small, indicating that other processes in empathy are of influence. Demonstrating the different associations of frequency and perceived severity with empathy was a first step. Future research can use the distinction between frequency and perceived severity to gain further insight into bullying and victimization in association with well-being, adjustment, health outcomes and school performance. For example, previous research has already established links of bullying and victimization with serious negative health outcomes (e.g., Rigby, 2000; Ttofi \& Farrington, 2008). It will be important to examine in future research whether certain types of adjustment problems are specifically linked to frequent or severe bullying and victimization.

A last potential limitation of the current study is that we did not exclude children who were involved in both bullying and victimization, a group of children identified as bully/victims. Previous research has demonstrated that bully/victims have difficulties across domains of social-cognitive functioning (Toblin, Schwartz, Hopmeyer Gorman, \& Abou-ezzeddine, 2005). However, the review of van Noorden et al. (2015) shows that bully/victims are generally found to be similar to bullies and victims in cognitive and affective empathy. Therefore, it is unlikely that the inclusion of bully/victims has biased this study.

\section{Practical Implications}

This study provides evidence for a distinction between the frequency and perceived severity of bullying and victimization. This implies that the frequency does not necessarily determine the perceived severity of bullying and victimization. Therefore, we would like to advise teachers, parents, peers, and researchers to attend to the perceived severity of bullying and victimization, in addition to the frequency of these behaviors. One should not merely focus on frequency and simply assume that children are less affected by occasional bullying than by frequent bullying. Moreover, bullying interventions programs may want to re-evaluate their sole reliance on the frequency of bullying and victimization. The effectiveness of such programs may be underestimated when interpreting the small, or absent, decrease in the frequency in bullying and victimization, despite a potential larger decrease in the perceived severity of incidents. Therefore, we recommend including measures of the perceived severity of bullying and in particular victimization, in addition to measures of frequency in research on the effects of implemented interventions.

\section{References}

Belacchi, C., \& Farina, E. (2012). Feeling and thinking of others: Affective and cognitive empathy and emotion comprehension in prosocial/hostile preschoolers. Aggressive Behavior, 38, 150-165. doi: 10.1002/ab.21415

Borg, M. G. (1999). The extent and nature of bullying among primary and secondary schoolchildren. Educational Research, 41, 137-153. doi: 10.1080/0013188990410202 
Boulton, M. J., \& Underwood, K. (1992). Bully/victim problems among middle school children. British Journal of Educational Psychology, 62, 73-87. doi: 10.1111/j.20448279.1992.tb01000.x

Bouman, T., van der Meulen, M., Goossens, F. A., Olthof, T., Vermande, M. M., \& Aleva, E. A. (2012). Peer and self-reports of victimization and bullying: Their differential association with internalizing problems and social adjustment. Journal of School Psychology, 50, 759-774. doi: 10.1016/j.jsp.2012.08.004

Branson, C. E., \& Cornell, D. G. (2009). A comparison of self and peer reports in the assessment of middle school bullying. Journal of Applied School Psychology, 25, 5-27. doi: 10.1080/15377900802484133

Caravita, S. C. S., Di Blasio, P., \& Salmivalli, C. (2009). Unique and interactive effects of empathy and social status on involvement in bullying. Social Development, 18, 140-163. doi: 10.1111/j.1467-9507.2008.00465.x

Caravita, S. C. S., Di Blasio, P., \& Salmivalli, C. (2010). Early adolescents' participation in bullying: Is ToM involved? Journal of Early Adolescence, 30, 138-170. doi: 10.1177/ 0272431609342983

Chen, L. M., Cheng, Y. Y., Wang, W. C., \& Hsueh, C.-W. (2013). The intersection between perceived severity and frequency of being bullied: A Rasch measurement approach. Educational Psychology, 1-19. doi: 10.1080/01443410.2013.864755

Ciucci, E., \& Baroncelli, A. (2014). The emotional core of bullying: Further evidences of the role of callous-unemotional traits and empathy. Personality and Individual Differences, 67, 69-74. doi: 10.1016/j.paid.2013.09.033

Cohen, D., \& Strayer, J. (1996). Empathy in conduct-disordered and comparison youth. Developmental Psychology, 32, 988-998. doi: 10.1037/0012-1649.32.6.988

Davis, M. H. (1983). Measuring individual differences in empathy: Evidence for a multidimensional approach. Journal of Personality and Social Psychology, 44, 113-126. doi: 10.1037/0022-3514.44.1.113

Eisenberg, N., \& Miller, P. A. (1987). The relation of empathy to prosocial and related behaviors. Psychological Bulletin, 101, 91-119. doi: 10.1037/0033-2909.101.1.91

Farrington, D. P., \& Ttofi, M. M. (2009). School-based programs to reduce bullying and victimization. Campbell Systematic Reviews, 6. doi: 10.4073/csr.2009.6

Hogan, R. (1969). Development of an empathy scale. Journal of Consulting and Clinical Psychology, 33, 307-316. doi: 10.1037/h0027580

Jolliffe, D., \& Farrington, D. P. (2004). Empathy and offending: A systematic review and meta-analysis. Aggression and Violent Behavior, 9, 441-476. doi: 10.1016/ j.avb.2003.03.001

Jolliffe, D., \& Farrington, D. P. (2006a). Development and validation of the Basic Empathy Scale. Journal of Adolescence, 29, 589-611. doi: 10.1016/j.adolescence.2005.08.010

Jolliffe, D., \& Farrington, D. P. (2006b). Examining the relationship between low empathy and bullying. Aggressive Behavior, 32, 540-550. doi: 10.1002/Ab.20154

Jolliffe, D., \& Farrington, D. P. (2011). Is low empathy related to bullying after controlling for individual and social background variables? Journal of Adolescence, 34, 59-71. doi: 10.1016/j.adolescence.2010.02.001

Kokkinos, C. M., \& Kipritsi, E. (2012). The relationship between bullying, victimization, trait emotional intelligence, self-efficacy and empathy among preadolescents. Social Psychology of Education, 15, 41-58. doi: 10.1007/s11218-011-9168-9

Leith, K. P., \& Baumeister, R. F. (1998). Empathy, shame, guilt, and narratives of interpersonal conflicts: Guilt-prone people are better at perspective taking. Journal of Personality, 66, 1-37. doi: 10.1111/1467-6494.00001

Lovett, B. J., \& Sheffield, R. A. (2007). Affective empathy deficits in aggressive children and adolescents: A critical review. Clinical Psychology Review, 27, 1-13. doi: 10.1016/ j.cpr.2006.03.003

Maunder, R. E., Harrop, A., \& Tattersall, A. J. (2010). Pupil and staff perceptions of bullying in secondary schools: Comparing behavioural definitions and their perceived seriousness. Educational Research, 52, 263-282. doi: 10.1080/00131881.2010.504062

Mehrabian, A., \& Epstein, N. (1972). A measure of emotional empathy. Journal of Personality, 40, 525-543. doi: 10.1111/j.1467-6494.1972.tb00078.x 
Miller, P. A., \& Eisenberg, N. (1988). The relation of empathy to aggressive and externalizing/antisocial behavior. Psychological Bulletin, 103, 324-344. doi: 10.1037/00332909.103.3.324

Olweus, D. (1996). Bullying at school: Knowledge base and an effective intervention program. Annals of the New York Academy of Sciences, 794, 265-276. doi: 10.1111/j.17496632.1996.tb32527.x

Olweus, D. (2010). Understanding and researching bullying: Some critical issues. In S. R. Jimerson, S. M. Swearer, \& D. L. Espelage (Eds.), Handbook of bullying in schools. New York: Routhledge.

Park, J. H. (2013). Differential correlates of bully/victim status and bystander roles of school violence with school adjustment in Korea. KEDI Journal of Educational Policy, Special Issue, 119-133.

Poteat, V. P., \& Espelage, D. L. (2005). Exploring the relation between bullying and homophobic verbal content: The Homophobic Content Agent Target (HCAT) scale. Violence and Victims, 20, 513-528. doi: 10.1891/vivi.2005.20.5.513

Raskauskas, J. (2005). Bullying on the school bus. Journal of School Violence, 4, 93-107. doi: $10.1300 / \mathrm{J} 202 \mathrm{v} 04 \mathrm{n} 03$ _08

Rigby, K. (2000). Effects of peer victimization in schools ad perceived social support on adolescent well-being. Journal of Adolescence, 23, 57-68. doi: 10.1006/ jado.1999.0289

Rose, A. J., \& Rudolph, K. D. (2006). A review of sex differences in peer relationship processes: Potential trade-offs for the emotional and behavioral development of girls and boys. Psychological Bulletin, 132, 98-131. doi: 10.1037/0033-2909.132.1.98

Salmivalli, C. (2010). Bullying and the peer group: A review. Aggression and Violent Behavior, 15, 112-120. doi: 10.1016/j.avb.2009.08.007

Salmivalli, C., \& Peets, K. (2009). Bullies, victims, and bully-victim relationships in middle childhood and early adolescence. In K. H. Rubin, W. M. Bukowski, \& B. Laursen (Eds.), Handbook of peer interactions, relationships, and groups (pp. 322-340). New York: Guilford.

Scheithauer, H., Hayer, T., Petermann, F., \& Jugert, G. (2006). Physical, verbal, and relational forms of bullying among German students: Age trends, gender differences, and correlates. Aggressive Behavior, 32, 261-275. doi: 10.1002/ab.20128

Slee, P. T. (1994). Situational and interpersonal correlates of anxiety associated with peer victimisation. Child Psychiatry and Human Development, 25, 97-107. doi: 10.1007/ BF02253289

Stassen Berger, K. (2007). Update on bullying at school: Science forgotten? Developmental Review, 27, 90-126. doi: 10.1016/j.dr.2006.08.002

Stavrinides, P., Georgiou, S., \& Theofanous, V. (2010). Bullying and empathy: A short-term longitudinal investigation. Educational Psychology, 30, 793-802. doi: 10.1080/ 01443410.2010 .506004

Sticca, F., \& Perren, S. (2013). Is Cyberbullying worse than traditional bullying? Examining the differential roles of medium, publicity, and anonymity for the perceived severity of bullying. Journal of Youth and Adolescence, 42, 739-750. doi: 10.1007/s10964-0129867-3

Sticca, F., Ruggieri, S., Alsaker, F., \& Perren, S. (2013). Longitudinal risk factors for cyberbullying in adolescence. Journal of Community and Applied Social Psychology, 23, 5267. doi: 10.1002/casp. 2136

Toblin, R. L., Schwartz, D., Hopmeyer Gorman, A., \& Abou-ezzeddine, T. (2005). Socialcognitive and behavioral attributes of aggressive victims of bullying. Journal of Applied Developmental Psychology, 26, 329-346. doi: 10.1016/j.appdev.2005.02.004

Ttofi, M. M., \& Farrington, D. P. (2008). Bullying: Short-term and long-term effects, and the importance of defiance theory in explanation and prevention. Victims \& Offenders, 3, 289-312. doi: 10.1080/15564880802143397

Tukey, J. W. (1977). Exploratory data analysis. Reading, MA: Addison Wesley.

van den Berg, Y. H. M., \& Cillessen, A. H. N. (2013). Computerized sociometric and peer assessment: An empirical and practical evaluation. International Journal of Behavioral Development, 37, 68-76. doi: 10.1177/0165025412463508 
van Noorden, T. H. J., Haselager, G. J. T., Cillessen, A. H. N., \& Bukowski, W. M. (2014). Dehumanization in children: The link with moral disengagement in bullying and victimization. Aggressive Behavior, 40, 320-328. doi: 10.1002/ab.21522

van Noorden, T. H. J., Haselager, G. J. T., Cillessen, A. H. N., \& Bukowski, W. M. (2015). Empathy and involvement in bullying in children and adolescents: A systematic review. Journal of Youth and Adolescence, 44, 637-657. doi: 10.1007/s10964-014-0135-6

Whitney, I., \& Smith, P. K. (1993). A survey of the nature and extent of bullying in junior/ middle and secondary schools. Educational Research, 35, 3-25. doi: 10.1080/ 0013188930350101

Williford, A., Boulton, A. J., \& Jenson, J. M. (2014). Transitions between subclasses of bullying and victimization when entering middle school. Aggressive Behavior, 40, 24-41. doi: $10.1002 / \mathrm{ab} .21503$

\section{Author Notes}

Tirza H. J. van Noorden, Behavioural Science Institute, Radboud University Nijmegen, The Netherlands; William M. Bukowski, Centre de Recherche sur Développement Humain and Department of Psychology, Concordia University, Montreal, Canada; Gerbert J. T. Haselager, Behavioural Science Institute, Radboud University Nijmegen, The Netherlands; Tessa A. M. Lansu, Behavioural Science Institute, Radboud University Nijmegen, The Netherlands; Antonius H. N. Cillessen, Behavioural Science Institute, Radboud University Nijmegen, The Netherlands. 